Vol. 5, No. 1, 2019

Vitaliy Korendiy ${ }^{1}$, Roman Zinko ${ }^{2}$, Diana Muzychka ${ }^{3}$

1. Department of Mechanics and Automation Engineering, Lviv Polytechnic National University, Ukraine, Lviv,

S. Bandery street 12, E-mail: vitaliy.nulp@gmail.com, ORCID 0000-0002-6025-3013

2. Department of Automotive Engineering, Lviv Polytechnic National University, Ukraine, Lviv, S. Bandery street 12, E-mail: rzinko@gmail.com, ORCID 0000-0002-3275-8188

3. Department of Machine-Building Technology, Dniprovsky State Technical University, Ukraine, Kamyanske, Dniprobudivska street 2, E-mail: muzichka@ua.fm, ORCID 0000-0002-2914-9672

\title{
SUBSTANTIATION OF STRUCTURE AND PARAMETERS OF PNEUMATIC SYSTEM OF MOBILE ROBOT WITH ORTHOGONAL WALKING DRIVE
}

Received: November 24, 2018 / Revised: February 20, 2019 / Accepted: June 26, 2019

(C) Korendiy V., Zinko R., Muzychka D., 2019

\begin{abstract}
Problem statement. Mobile robots have awoken a large interest between scientists and designers in the last few years. One of the prospective drives of such robots is based on pneumatically operated system with no use of electric, heat, magnetic or other types of energy. Purpose. The main purpose of this research consists in substantiation of structure and parameters of pneumatic system of mobile robot with orthogonal walking drive. Methodology. The research is carried out using the basic laws and principles of mechanics, pneumatics and automation. The numerical experiment is conducted in MathCAD software and computer simulation of the robot's motion is performed using SolidWorks software. Findings (results) and originality (novelty). The improved structure of the mobile robot with orthogonal walking drive is proposed. The pneumatically operated system ensuring the robot's motion is substantiated. Practical value. The proposed design of walking robot can be used while designing industrial (production) prototypes of mobile robotic systems for performing various activities in the environments that are not suitable for using electric power. Scopes of further investigations. While carrying out further investigations, it is necessary to ensure the possibility of changing motion direction of mobile robot by means of pneumatic drive. In addition, it is expedient to design the devices for changing motion speed of the robot and the height of lifting of its feet.
\end{abstract}

Keywords: mobile robot, walking drive, pneumatic system, simulation, timing diagram, numerical modelling, motion speed, control system.

\section{Introduction}

Modern mobile robots are of the products that have significant export potential, which can cover (compensate) the expenses related with their designing and manufacturing, and realize a profit due to their selling abroad. Therefore, in many developed countries, companies with advanced information and production technologies aspire to develop industrial prototypes of competitive mobile robots for various purposes, in particular, for performing military, technological and exploratory operations.

\section{Problem Statement}

One of the major problems arising while carrying out the research and designing of mobile robots consists in choosing the correct type of drive. Nowadays, most robots use wheeled or caterpillar drive powered by electricity. In some cases (e. g., in some gaseous of fluid mediums), the use of electricity is prohibited. On the other hand, the use of wheeled or caterpillar drives in various agricultural machines is harmful for the fertile soil surface. That is why mobile technological machines based on walking drives are of significant interest among researchers, designers and consumers all over the world. 


\section{Vitaliy Korendiy, Roman Zinko, Diana Muzychka}

\section{Review of Modern Information Sources on the Subject of the Paper}

Nowadays, the problems of designing, manufacturing, and operation of mobile robotic systems are widely investigated by scientists all over the world [1]-[11]. Most of them deal with drives powered by electricity [1]-[10], whereas, in the present paper, the pneumatically operated robot will be considered. The general structure of the considered robot is similar to the ones presented in [5]-[10]. The main difference between the proposed design and the designs presented in [5]-[10] consist in the use of pneumatic drive and corresponding control system, whereas the kinematic diagrams of the robots are almost the same. For the first time, the basic structure of the proposed robot, as well as its operation conditions, were presented at the $14^{\text {th }}$ International Symposium of Ukrainian Mechanical Engineers in Lviv [11]. This paper presents more detailed results of investigations related with control and operation of the pneumatically operated mobile robot with orthogonal walking drive.

\section{Objectives and Problems of Research}

The main purpose of the paper consists in substantiation of structure and control system of the eightleg mobile robotic system with pneumatic drive and orthogonal walking movers. In order to reach the mentioned goal it is necessary to solve the following problems: to propose the improved design of the robot; to analyse the process of the robot's motion (cyclic walking); to substantiate the timing diagram (cyclogram) of operation of pneumatic cylinders and to develop the control system of pneumatic drive; to derive the laws of motion of the robot's members; to simulate the robot's motion using the derived analytical expressions and with a help of its solid-state model designed in SolidWorks software.

\section{Structural Peculiarities of the Proposed Mobile Robotic System}

One of the simplest designs of mobile robotic systems with orthogonal walking drive is presented in Fig. 1. The robot consists of two movable platforms 1 and 2, which are allowed to move about the frame (body) 10 along two horizontal roller guides 11 and 12, respectively. The straight-line cyclic motion of the platforms 1 and 2 is ensured with a help of two pneumatic cylinders 3 and 4, respectively. Such a structure of the horizontal drive of platforms ensures the increase of the robot's step length (i. e., the increase of its displacement during one operation cycle of the driving pneumatic system). On each of four edges of the load-carrying platforms 1 and 2, there are vertically fixed four synchronized pneumatic cylinders 5 and 6 , respectively. The total number of vertically operating pneumatic cylinders is eight, and the cylinders of each pair operate synchronously. The supports 7 and 8 are rigidly fixed to the rods (pins) of the pneumatic cylinders 5 and 6 . The supports act upon the supporting surface with a help of the corresponding feet. In order to ensure the relative motion of the platforms, the supporting feet of one platform are placed at a greater distance from each other. At the same time, the width of the other platform is smaller. This allows the motion of one platform between the supports of the other one.

The cyclic straight-line motion of the robotic system can be explained in the following way. The supporting feet 7 of one platform are in contact with supporting surface. In such a state, the rods (pins) of corresponding pneumatic cylinders 5 are maximally extended. The rods (pins) of vertical pneumatic cylinders 6 of the other platform are retracted, i. e. the feet 8 are lifted above the supporting surface. At the same time, the rods (pins) of the pneumatic cylinders 3 and 4 of horizontal displacement of the platforms 1 and 2 begin retracting and provide the motion of the platform 2 with the frame 9 to the left relative to the platform 1. When this motion is finished, the feet 8 of the platform 2 go down till the moment of contact with the supporting surface. The rods (pins) of the pneumatic cylinders 3 and 4 of horizontal displacement remain at rest. When the feet 8 touch the supporting surface, the feet 7 begin lifting, and the rods (pins) of the pneumatic cylinders 3 and 4 of the platforms' horizontal displacement begin retracting. This provide the motion of the platform 1 to the left relative to the platform 2 . Then the walking cycle is analogously repeated with the platform 1 .

At the following stages of the investigation it is necessary to analyse the process of cyclic walking of the mobile robot, to substantiate the timing diagram (cyclogram) of operation of pneumatic cylinders and to develop the control system of pneumatic drive. 


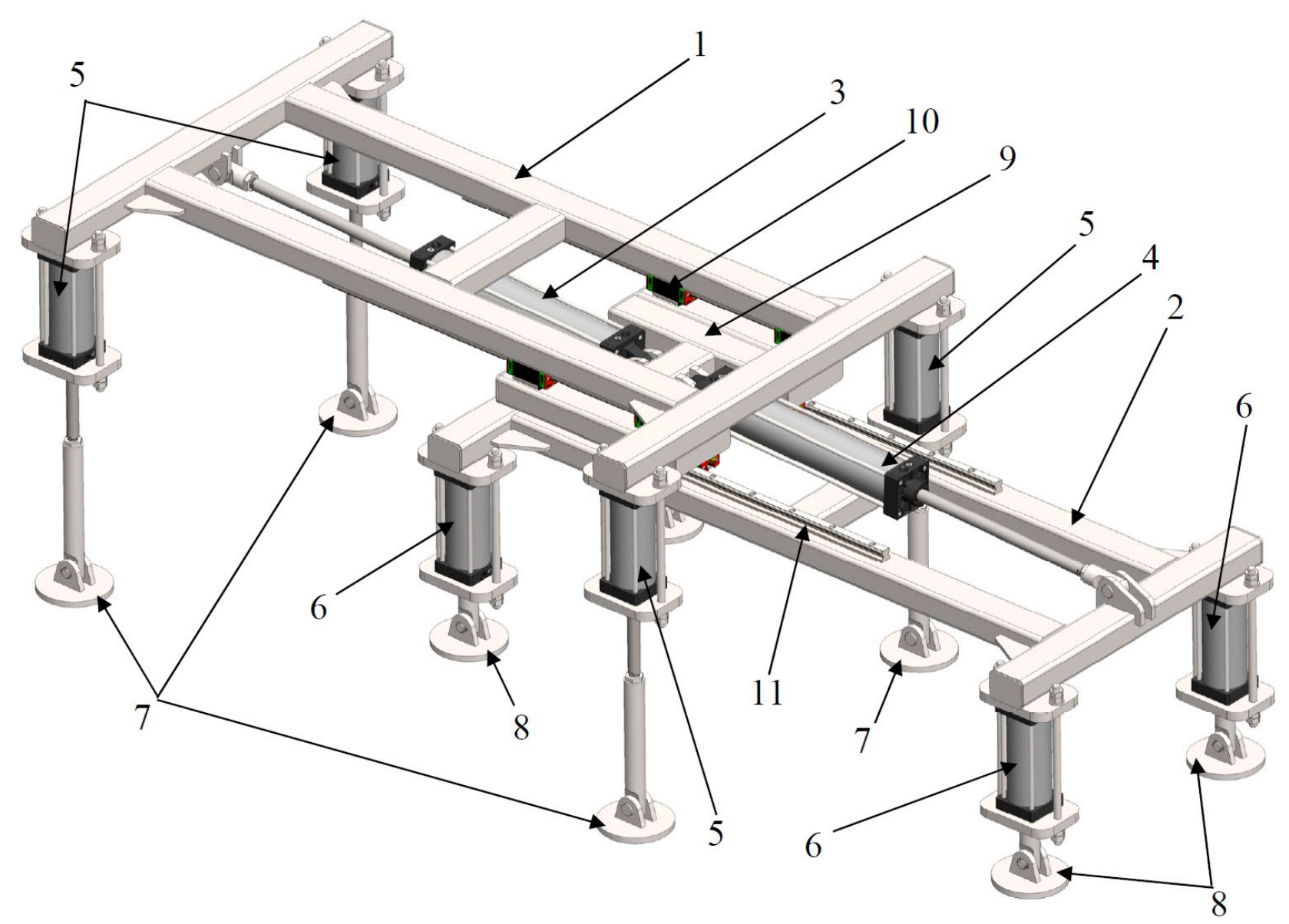

Fig. 1. Mobile robotic system with pneumatic drive and straight-line walking motion of load-carrying platforms

\section{Analysis of Process of Cyclic Walking of Mobile Robot}

Let us consider the basic motion cycles of mobile robotic system with orthogonal walking drive. The first cycle (Fig. 2, a) begins at the moment when the feet of one platform are in contact with supporting surface. At the same time, the feet of the other platform begin going down, and pneumatic cylinders of platforms' horizontal displacement are operating providing the motion of the inner platform to the left relative to the outer platform.

The second cycle of the walking process (Fig. 2, b) begins at the moment when the feet of the second platform reach the lowest endpoint. At the same time, there begins the lifting of the feet of the first platform, which has been supporting the robot's body during the first cycle. The first platform begins moving relative to the second (supporting) platform due to the operation of the pneumatic cylinders of platforms' horizontal displacement.

The third cycle of the walking process (Fig. 2, c) begins at the moment when the feet of the first platform reach the highest endpoint, and the pneumatic cylinders of the platforms' horizontal displacement move the movable platform maximally to the left relative to the supporting (immovable) platform. At the same time, there begins the lowering of the feet of the first platform till the moment of their contact with the supporting surface.

The fourth cycle of the walking process (Fig. 2, d) begins at the moment when the feet of the first platform reach the lowest endpoint (i.e. when they are in contact with the supporting surface). Herewith, there is no motion of one platform relative to another one, and the feet of the second platform begin lifting from the lowest endpoint to the highest one.

After the fourth cycle, the system turns to the initial (starting) position (Fig. 2, e), and the walking cycles repeat: the end positions of the rods (pins) of the pneumatic cylinders in the fourth cycle correspond to the initial positions of the rods (pins) in the first walking cycle. 
Vitaliy Korendiy, Roman Zinko, Diana Muzychka
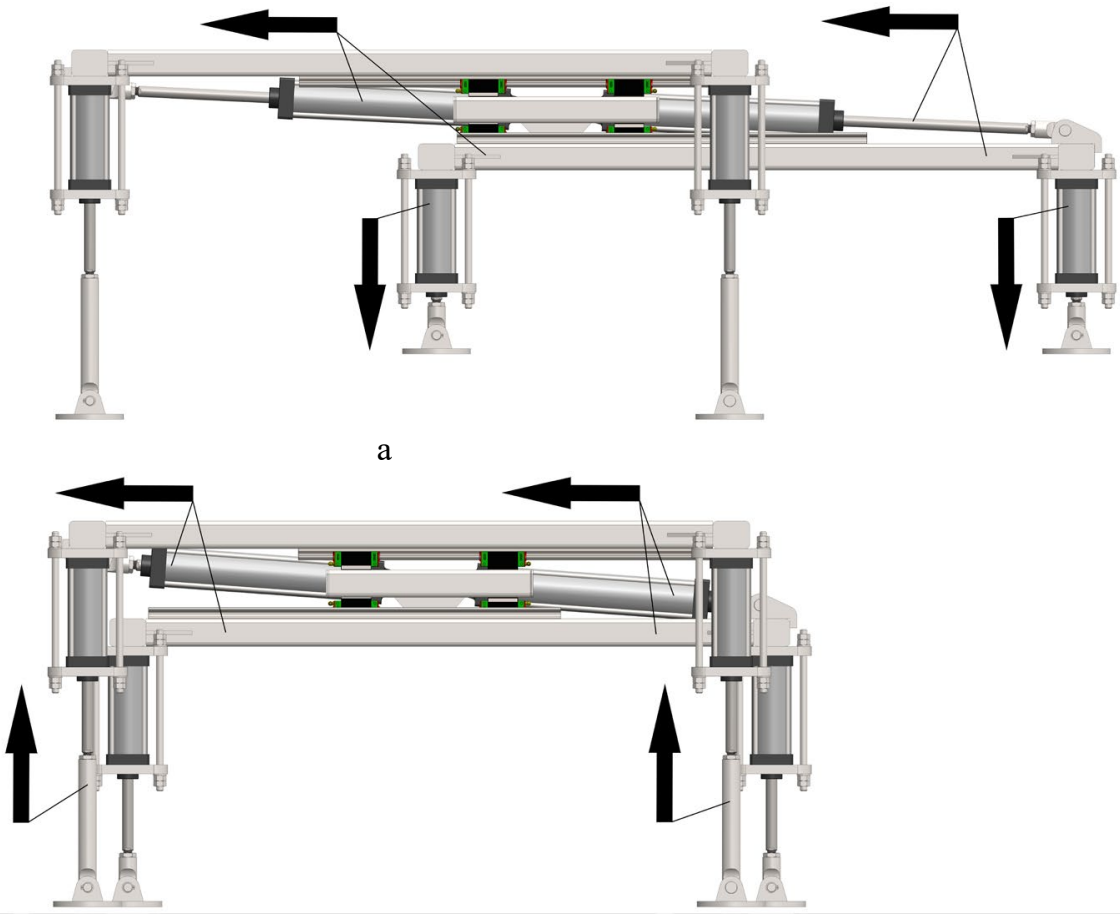

b

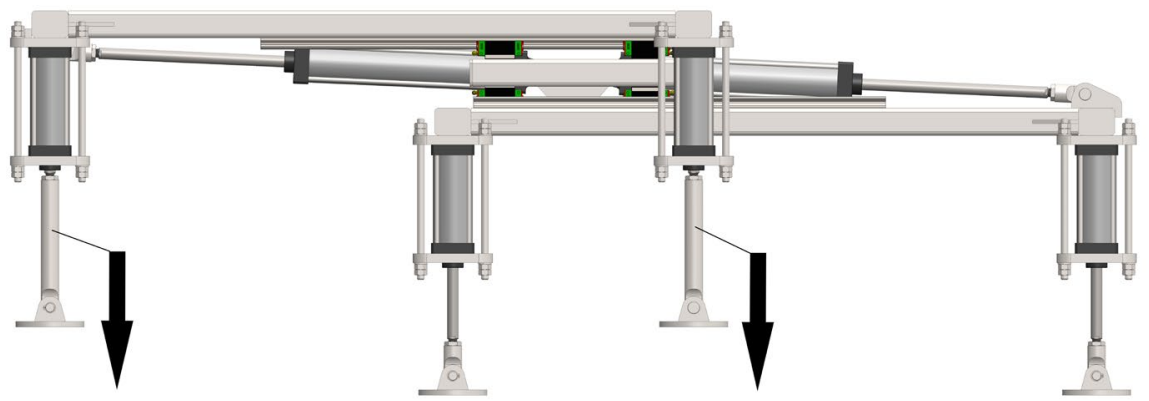

$\mathrm{c}$

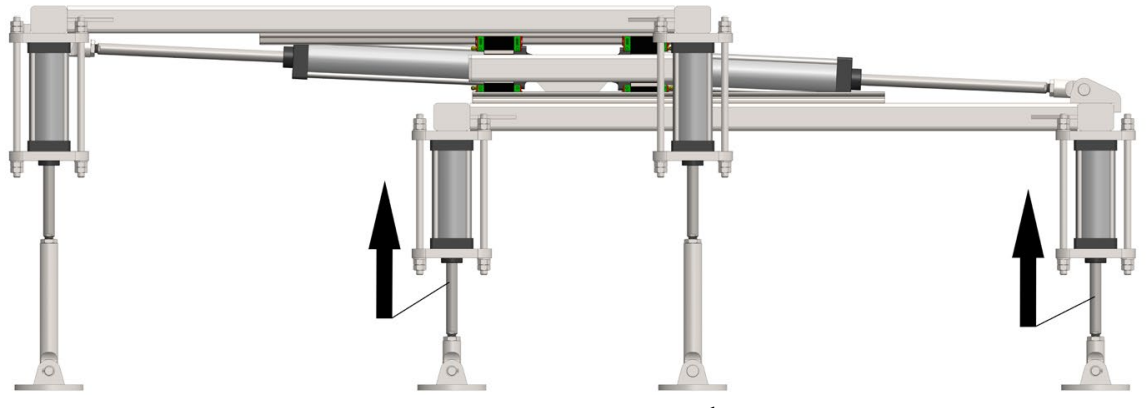

d

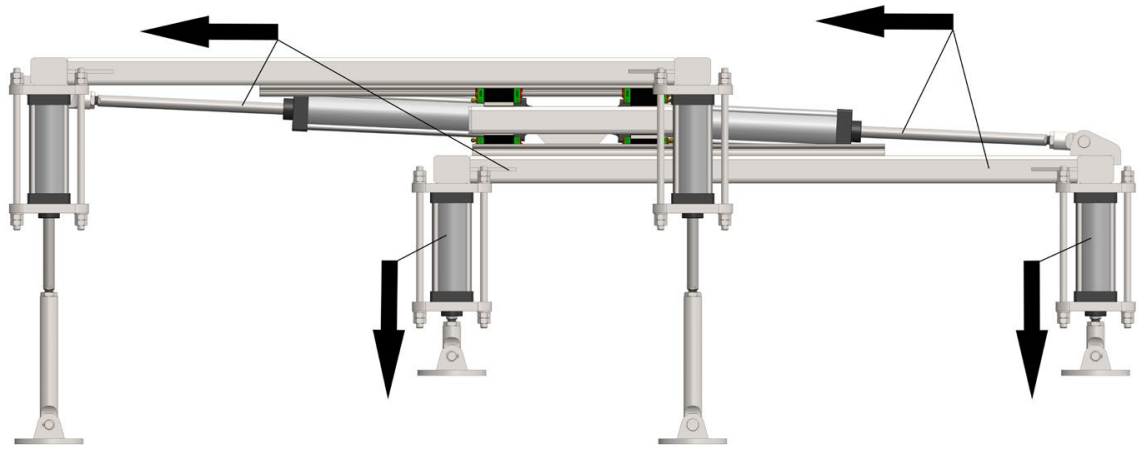

Fig. 2. Graphical interpretation of the main motion cycles of mobile robotic system with orthogonal walking drive 


\section{Substantiation of Structure and Parameters of Pneumatic System of Mobile Robot ...}

\section{Formation of Timing Diagram of Operation of Pneumatic Cylinders}

On the basis of the previously considered motion process of the mobile (walking) robot (Fig. 2), let us form timing diagram (cyclogram) of operation of its pneumatic drive. The pneumatic drive consists of four systems of pneumatic cylinders. Two systems consist of four synchronized pneumatic cylinders and are used for lifting/lowering of supporting feet. The other two systems are used for horizontal displacement of two movable platforms.

The first cycle of operation of pneumatic drive should provide the following operations (Fig. 3): a) "delay" ("stoppage") of vertical pneumatic cylinders of the robot's active platform (this means that one platform is immovably staying on the supporting surface); b) motion of the rods (pins) of the horizontal pneumatic cylinders of the active and passive platforms (the rods (pins) of both cylinders perform reverse run or are in back stroke); c) going down (forward stroke, direct run) of the rods of the vertical cylinders of the passive platform (which does not act upon the supporting surface).

The second cycle of operation of pneumatic drive should provide the following operations (Fig. 3): a) "delay" ("stoppage") of vertical pneumatic cylinders of the robot's platform, which became active after the first cycle (this means that the second platform is immovably staying on the supporting surface); b) lifting (reverse run, back stroke) of the rods of the vertical pneumatic cylinders of the other platform, which became passive after the first cycle (which acted upon the supporting surface in the first cycle); c) motion of the rods of the horizontal pneumatic cylinders of the active and passive platforms in the opposite direction (the rods of both cylinders perform direct run or are in forward stroke).

The third cycle of operation of pneumatic drive should provide the following operations (Fig. 3): a) "delay" ("stoppage") of vertical pneumatic cylinders of the robot's platform, which became active after the first cycle and remained active during the second cycle (this means that the second platform is immovably staying on the supporting surface); b) lowering (forward stroke, direct run) of the rods of the vertical pneumatic cylinders of the platform, which became passive after the first cycle and remained passive at the second cycle (this platform did not act upon the supporting surface in the second cycle); c) "delay" ("stoppage") of the rods of the horizontal pneumatic cylinders of the active and passive platforms (because the passive platform have already moved relative to the active one at the distance that is equal to the length of one step).

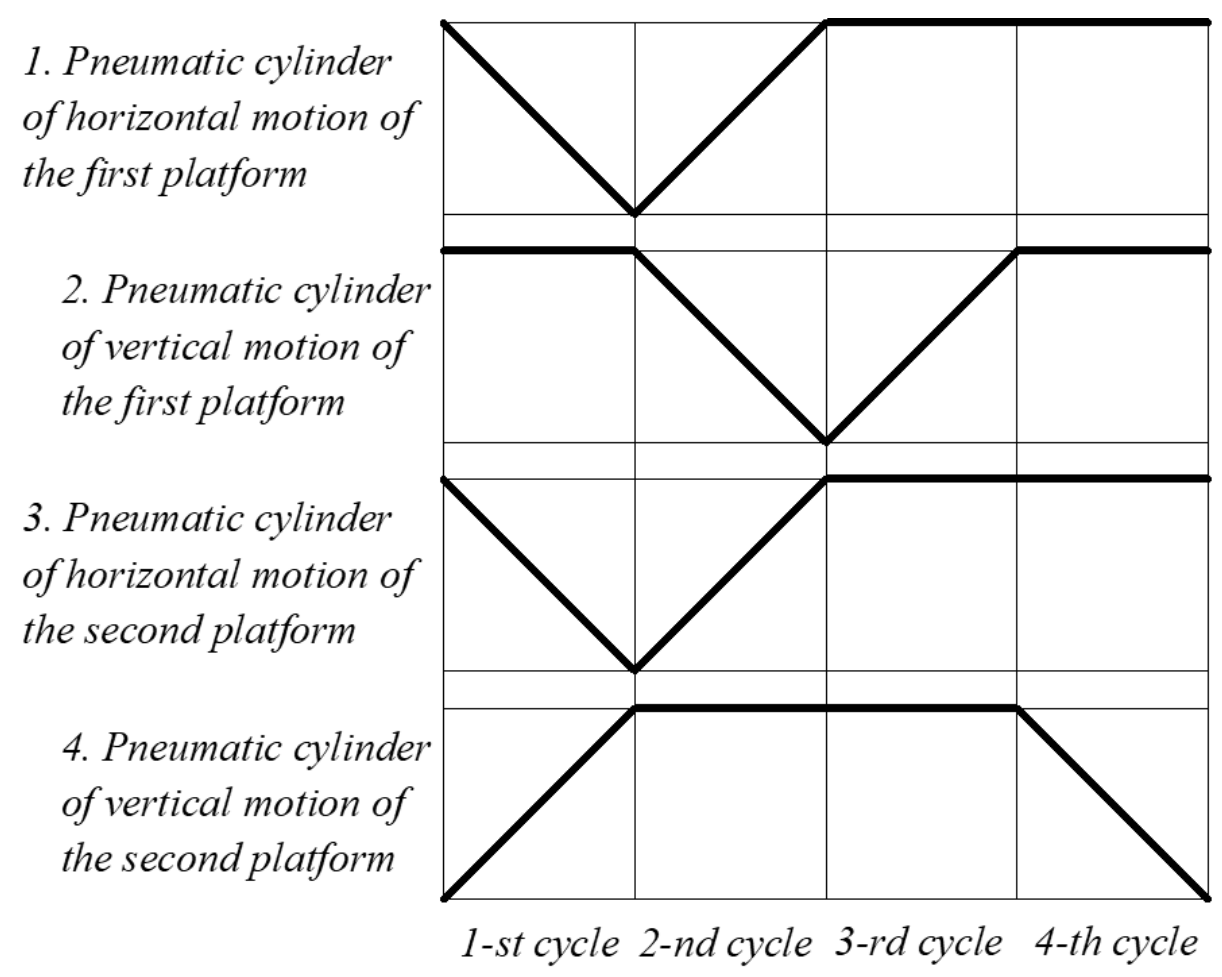

Fig. 3. Timing diagram of operation of the robot's pneumatic system 


\section{Vitaliy Korendiy, Roman Zinko, Diana Muzychka}

The fourth cycle of operation of pneumatic drive should provide the following operations (Fig. 3): a) "delay" ("stoppage") of vertical pneumatic cylinders of the robot's platform, which became active after the third cycle (this means that the first platform is immovably staying on the supporting surface); b) lifting (reverse run, back stroke) of the rods of the vertical pneumatic cylinders of the second platform, which became passive after the third cycle (this platform do not act upon the supporting surface in the fourth cycle); c) "delay" ("stoppage") of the rods of the horizontal pneumatic cylinders of the active and passive platforms (because the passive platform has already moved relative to the active one at the distance that is equal to the length of one step).

\section{Constructing a Pneumatic Circuit of the Robot's Drive}

On the basis of the considered timing diagram of operation of pneumatic cylinders of mobile robot (Fig. 3), let us construct the corresponding pneumatic circuit of the robot's drive (Fig. 4). The principal pneumatic circuit consists of the following components: four double-acting (two-way) cylinders providing direct and reverse run $\left(Д_{1}, Д_{2}, Д_{3}, Д_{4}\right)$; four two-position four-linear pneumatic control distribution valves $\left(P_{2}, P_{3}, P_{4}, P_{5}\right)$, eight two-position four-linear pneumatic distribution valves with end-sensors $\left(P_{6}, P_{7}, P_{8}\right.$, $\left.P_{9}, P_{10}, P_{11}, P_{12}, P_{13}\right)$, four logical adding (summing) elements $\left(I_{1}, I_{2}, I_{3}, I_{4}\right)$, starting distribution valve ("Start" button, $P_{1}$ ), and eight regulating (pilot) air-flow constrictor with check (non-return) valves for providing the possibility of changing the intensity of air-consumption.

The proposed pneumatic circuit ensures the operation of the pneumatic cylinders in accordance with the prescribed program (timing diagram, Fig. 3). After pushing the "Start" button, the air flows through the ports (passages) of the distribution valve $P_{12}$ if the piston of the cylinder $Д_{4}$ is located in the left end position. The air flows from the air-supply system to the control distribution valves $P_{2}, P_{4}, P_{5}$ providing the reverse run (back stroke) of the rods of the pneumatic cylinders $Д_{1}, Д_{3}$ and the direct run (forward stroke) of the rod of the cylinder $Д_{4}$. Taking into account the necessity to ensure the simultaneous operation of three pneumatic cylinders during the stroke 1 , two logical adding (summing) elements $I_{1}, I_{2}$ were used for registering the positions of the corresponding piston-rods with tappets during the stroke 1 . The output signal from $I_{2}$ switch the distribution valves $P_{2}, P_{3}, P_{4}$. This provides the direct run (forward stroke) of the pistons of the cylinders $Д_{1}, Д_{3}$ and the reverse run (back stroke) of the piston of the cylinder $Д_{2}$.

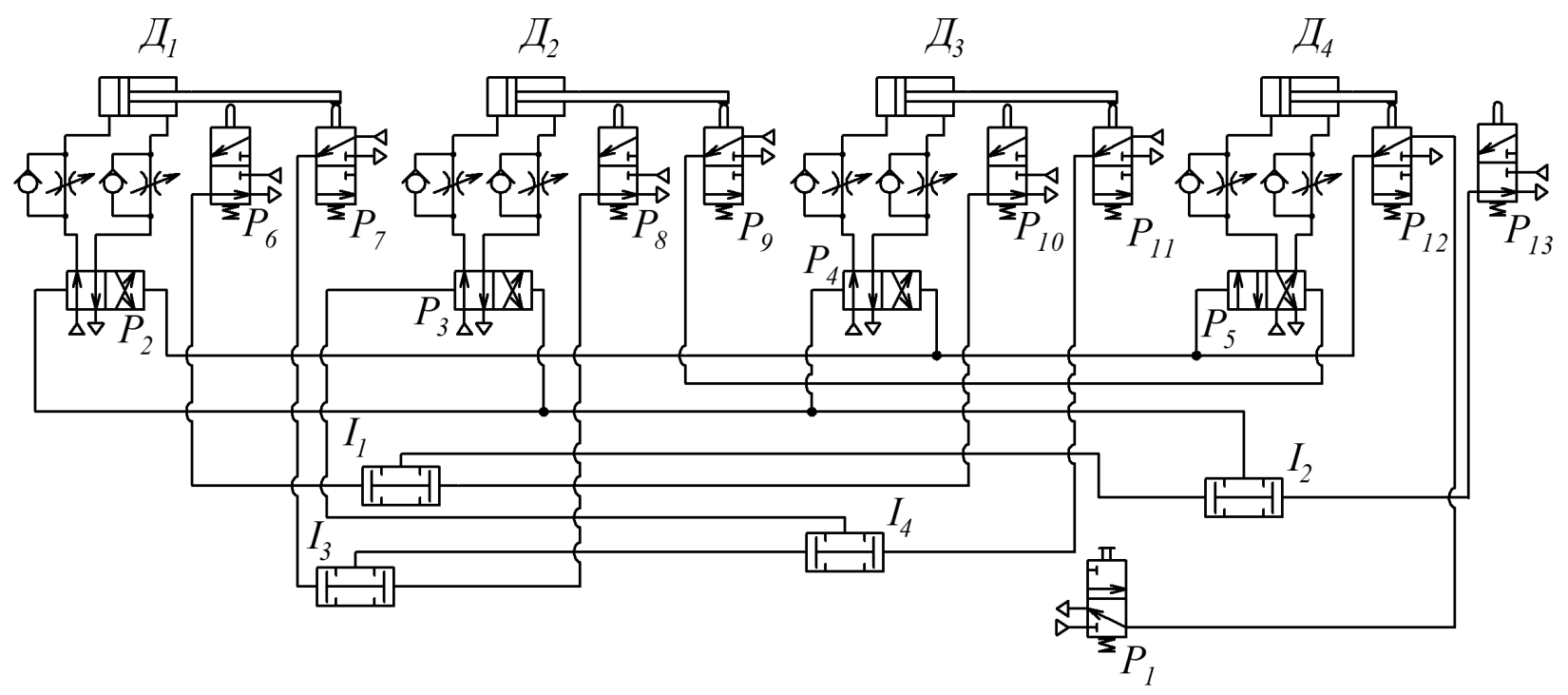

Fig. 4. Principal pneumatic circuit of the robot's drive

In order to start the stroke 3 , it is necessary to register the end of performing the stroke 2 . That is why the logical adding (summing) elements $I_{3}, I_{4}$ are used in the pneumatic circuit. These elements register the end of the stroke 2 and give a command for performing the stroke 3 (the direct run (forward stroke) of the piston of the cylinder $Д_{2}$ ). When the piston-rod of the cylinder $Д_{2}$ reaches its end-position, the distribution valve $P_{9}$ gives the command for performing the reverse run (back stroke) of the rod of the 


\section{Substantiation of Structure and Parameters of Pneumatic System of Mobile Robot ...}

cylinder $Д_{4}$ by switching the distribution valve $P_{5}$. At the end of the fourth stroke, the full cycle of the pneumatic system operation is performed. After this the following walking cycle is to be performed.

\section{Deriving the laws of motion of the robot's members}

On the basis of the constructed timing diagram of the mobile robot walking process (Fig. 3), let us derive the equations of motion of the robot's members. Let us make the following assumptions: 1) the duration $T$ of each cycle (stroke) of the robot's walking process is equal (unchanged); 2) the speed $V$ of motion of each piston-rod of all pneumatic cylinders in the forward and back stroke (direct and reverse run) is equal (for the pneumatic cylinders of the platforms' horizontal motion $V_{h}=\dot{x}_{1}=\dot{x}_{2}$; for the pneumatic cylinders of the feet vertical motion $\left.V_{v}=\dot{y}_{1}=\dot{y}_{2}\right)$; 3) the speed of motion of the rod of each pneumatic cylinder during one stroke is constant $\left(V_{h}=\right.$ const,$V_{v}=$ const $)$.

Taking into account the assumptions made, in accordance with the proposed timing diagram of the robot's pneumatic system operation (Fig. 3), let us derive the laws of motion of the load-carrying frame (body) and of the supporting feet $\left(x_{1}, x_{2}\right.$ are the related horizontal displacements of the movable platforms with respect to the load-carrying frame (body) of the robot; $y_{1}, y_{2}$ are the related vertical displacements of the supporting feet with respect to the corresponding platforms):

$$
\begin{aligned}
& x_{\text {frame }}(t)=\left\{\begin{array}{l}
\dot{x}_{1} \cdot t, 0 \leq t \leq T \text { (1-st stroke); } \\
\dot{x}_{1} \cdot T+\dot{x}_{2} \cdot(t-T), T \leq t \leq 2 \cdot T \text { (2-nd stroke); } \\
\left(\dot{x}_{1}+\dot{x}_{2}\right) \cdot T, 2 \cdot T \leq t \leq 3 \cdot T \text { (3-rd stroke); } \\
\left(\dot{x}_{1}+\dot{x}_{2}\right) \cdot T, 3 \cdot T \leq t \leq 4 \cdot T \text { (4-th stroke). }
\end{array}=\left\{\begin{array}{l}
V_{2} \cdot t, 0 \leq t \leq T ; \\
V_{2} \cdot T+V \cdot(t-T), T \leq t \leq 2 \cdot T ; \\
2 \cdot V_{2} \cdot T, 2 \cdot T \leq t \leq 3 \cdot T ; \\
2 \cdot V_{2} \cdot T, 3 \cdot T \leq t \leq 4 \cdot T .
\end{array}\right.\right. \\
& x_{\text {foot } 1}(t)=\left\{\begin{array}{l}
0,0 \leq t \leq T ; \\
\left(\dot{x}_{1}+\dot{x}_{2}\right) \cdot(t-T), T \leq t \leq 2 \cdot T ; \\
\left(\dot{x}_{1}+\dot{x}_{2}\right) \cdot T, 2 \cdot T \leq t \leq 3 \cdot T ; \\
\left(\dot{x}_{1}+\dot{x}_{2}\right) \cdot T, 3 \cdot T \leq t \leq 4 \cdot T .
\end{array}=\left\{\begin{array}{l}
0,0 \leq t \leq T ; \\
2 \cdot V_{2} \cdot(t-T), T \leq t \leq 2 \cdot T ; \\
2 \cdot V_{2} \cdot T, 2 \cdot T \leq t \leq 3 \cdot T ; \\
2 \cdot V_{2} \cdot T, 3 \cdot T \leq t \leq 4 \cdot T .
\end{array}\right.\right. \\
& x_{\text {foot } 2}(t)=\left\{\begin{array}{l}
\left(\dot{x}_{1}+\dot{x}_{2}\right) \cdot t, 0 \leq t \leq T ; \\
\left(\dot{x}_{1}+\dot{x}_{2}\right) \cdot T, T \leq t \leq 2 \cdot T ; \\
\left(\dot{x}_{1}+\dot{x}_{2}\right) \cdot T, 2 \cdot T \leq t \leq 3 \cdot T ; \\
\left(\dot{x}_{1}+\dot{x}_{2}\right) \cdot T, 3 \cdot T \leq t \leq 4 \cdot T .
\end{array}=\left\{\begin{array}{l}
2 \cdot V_{2} \cdot t, 0 \leq t \leq T ; \\
2 \cdot V_{2} \cdot T, T \leq t \leq 2 \cdot T \\
2 \cdot V_{2} \cdot T, 2 \cdot T \leq t \leq 3 \cdot T \\
2 \cdot V_{2} \cdot T, 3 \cdot T \leq t \leq 4 \cdot T
\end{array}\right.\right. \\
& y_{\text {foot } 1}(t)=\left\{\begin{array}{l}
-y_{1 \min }, 0 \leq t \leq T ; \\
-y_{1 \min }+\dot{y}_{1} \cdot(t-T), T \leq t \leq 2 \cdot T ; \\
{\left[\begin{array}{l}
-y_{1 \min }+\dot{y}_{1} \cdot T- \\
-\dot{y}_{1} \cdot(t-2 \cdot T)
\end{array}\right], 2 \cdot T \leq t \leq 3 \cdot T ;} \\
-y_{1 \min }, 3 \cdot T \leq t \leq 4 \cdot T .
\end{array}=\left\{\begin{array}{l}
-y_{1 \min }, 0 \leq t \leq T ; \\
-y_{1 \min }+V_{B} \cdot(t-T), T \leq t \leq 2 \cdot T ; \\
{\left[\begin{array}{l}
-y_{1 \min }+V_{B} \cdot T- \\
-V_{B} \cdot(t-2 \cdot T)
\end{array}\right], 2 \cdot T \leq t \leq 3 \cdot T ;} \\
-y_{1 \min }, 3 \cdot T \leq t \leq 4 \cdot T .
\end{array}\right.\right. \\
& y_{\text {foot } 2}(t)=\left\{\begin{array}{l}
-y_{2 \min }+\dot{y}_{1} \cdot T-\dot{y}_{1} \cdot t, 0 \leq t \leq T ; \\
-y_{2 \min }, T \leq t \leq 2 \cdot T ; \\
-y_{2 \min }, 2 \cdot T \leq t \leq 3 \cdot T ; \\
-y_{2 \min }+\dot{y}_{2} \cdot(t-3 \cdot T), 3 \cdot T \leq t \leq 4 \cdot T .
\end{array}=\left\{\begin{array}{l}
-y_{2 \min }+V_{B} \cdot T-V_{B} \cdot t, 0 \leq t \leq T ; \\
-y_{2 \min }, T \leq t \leq 2 \cdot T ; \\
-y_{2 \min }, 2 \cdot T \leq t \leq 3 \cdot T ; \\
-y_{2 \min }+V_{B} \cdot(t-3 \cdot T), 3 \cdot T \leq t \leq 4 \cdot T .
\end{array}\right.\right.
\end{aligned}
$$

In the formulas (1), the following notations were used: $y_{1 \text { min }}, y_{2 \min }$ are the maximal extensions of the rods of vertical pneumatic cylinders of the supporting feet (i.e. the lowest positions of the supporting feet on the vertical axis); $x_{\text {frame }}, x_{\text {foot } 1}, x_{\text {foot } 2}, y_{\text {foot } 1}, y_{\text {foot } 2}$ are the coordinates of the corresponding members of the robot's mechanical system. 
Vitaliy Korendiy, Roman Zinko, Diana Muzychka

\section{Numerical Modelling of the Robot's Motion in MathCAD Software}

Using the derived equations of motion of the considered mobile robot, let us simulate the displacements of its members in MathCAD software. Firstly, let us specify the input parameters of modelling: 1) nominal speed of the piston-rods of the pneumatic cylinders of horizontal motion of movable platforms $\left.V_{h}=0.395 \mathrm{~m} / \mathrm{s} ; 2\right)$ nominal speed of the piston-rods of the pneumatic cylinders of vertical motion of the supporting feet $V_{v}=0.075 \mathrm{~m} / \mathrm{s} ; 3$ ) duration of one walking cycle (stroke) $T=2 \mathrm{~s}$; 4) maximal extension of the piston-rods of the pneumatic cylinders of vertical motion of the supporting feet $y_{1 \min }=y_{2 \min }=0.15 \mathrm{~m}$.

Taking into account the specified above parameters of the pneumatic system of the mobile robot, the time dependencies of vertical and horizontal coordinates of the supporting feet of the walking mechanism and the motion trajectories (paths) of the supporting feet are presented in Fig. 5 for the first three steps.
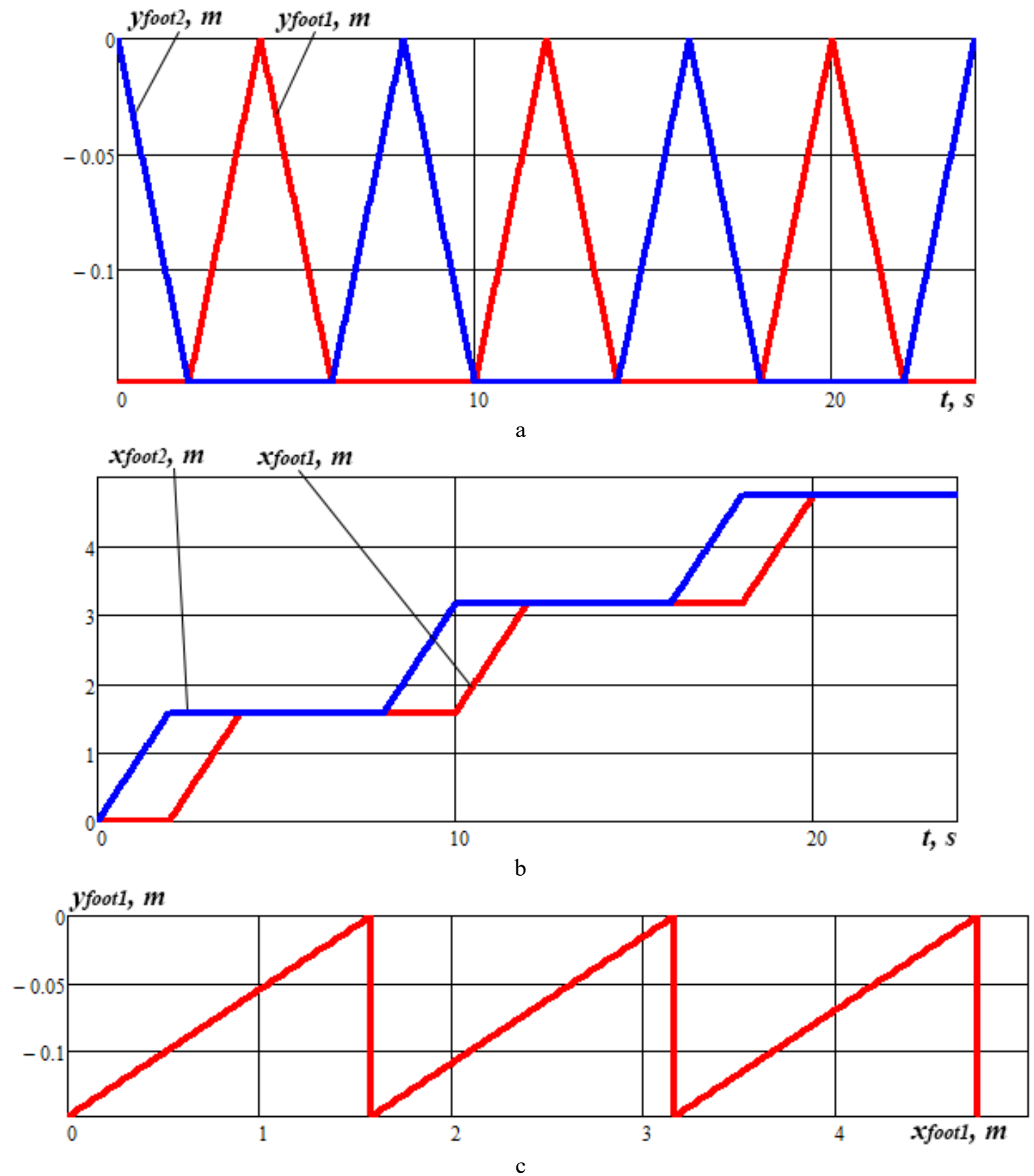

Fig. 5. Time dependencies of changing the coordinates of the robot's supporting feet $(a, b)$ and the motion trajectory (path) of the supporting foot (c) 


\section{Substantiation of Structure and Parameters of Pneumatic System of Mobile Robot ...}

Based on the obtained results we can conclude: 1) the proposed timing diagram of the pneumatic system operation (Fig. 3) is accurately described by the derived equations of the robot's members motion $(1) ; 2)$ at each moment of time, the supporting feet of at least one platform are in contact with the supporting surface; 3 ) the supporting feet of different platforms are not at the same walking phase during the whole walking process; 4 ) the step length during one cycle of the pneumatic system operation ( $8 \mathrm{~s}$ ) equals $1.58 \mathrm{~m}$. Therefore, the average speed of the robot's motion is $0.2 \mathrm{~m} / \mathrm{s}$ or $0.7 \mathrm{~km} / \mathrm{h} ; 5$ ) the maximal height of the supporting feet lifting (i.e. the maximal height of the obstacle that can be overcome by the robot) is equal to the maximal extension of the corresponding pneumatic cylinder $-0.15 \mathrm{~m}$.

\section{Simulation of the Robot's Motion in SolidWorks Software}

In order to substantiate the adequacy of the proposed theoretical models and of the results of numerical modelling of the mobile robotic system motion, let us perform the virtual experiment (simulation). First, the solid-state model of the eight-feet orthogonal walking robot was designed in SolidWorks software (Fig. 1, Fig. 6). For carrying out the engineering analysis of different mechanical system, the SolidWorks Motion environment was used. It allows modelling (simulating) the motion of program-controlled mechanisms (in this case - the robot's walking mechanism).

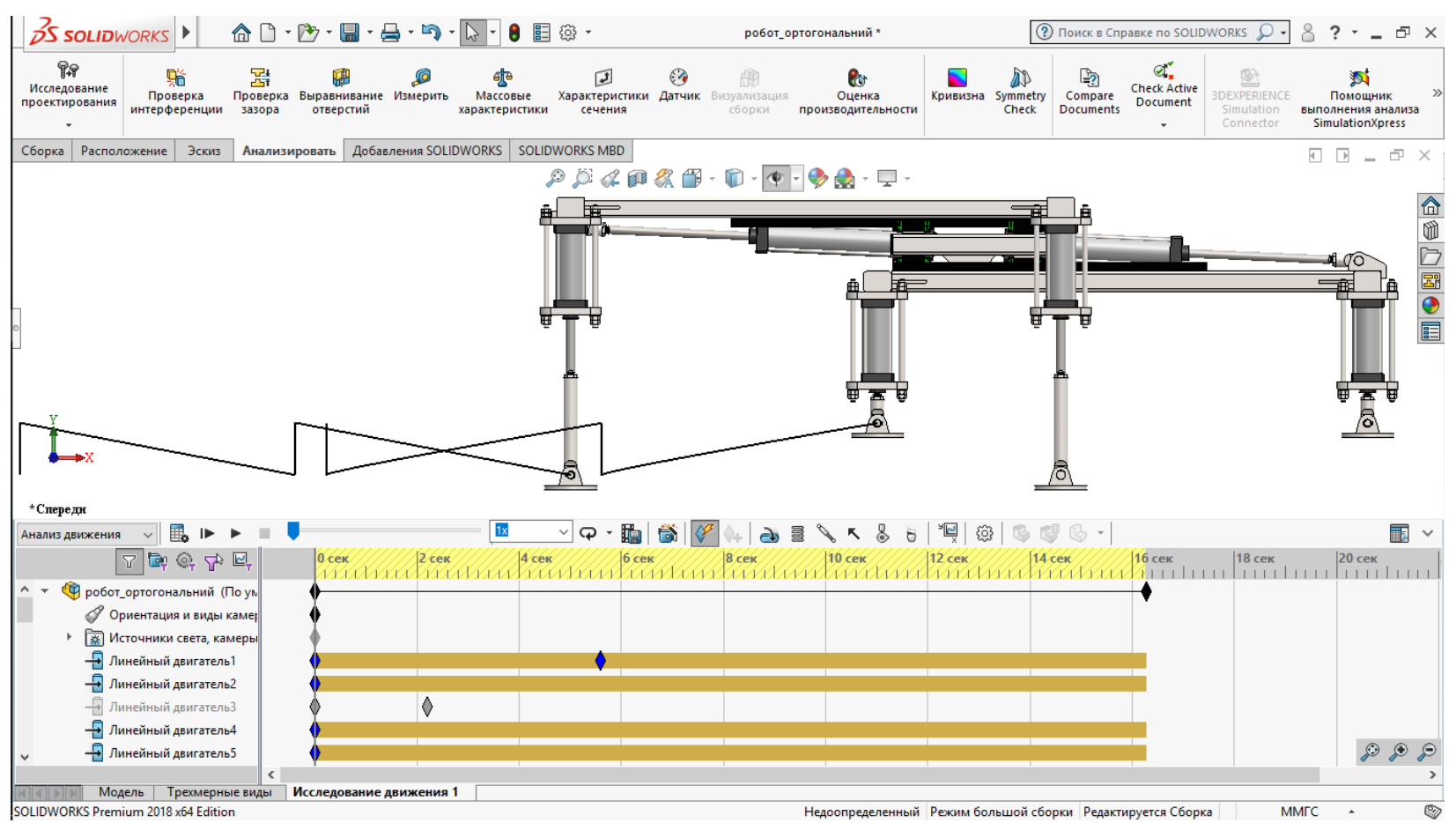

Fig. 6. SolidWorks software window, in which the simulation of the robot's motion has been carried out

Specifying the same input simulation parameters as for the numerical modelling, the motion of the mobile robot's solid-state model is simulated in SolidWorks Motion software. The main results of computer (virtual) experiments (time dependencies of changing the coordinates of the supporting feet) are presented in Fig. 7. The trajectories (paths) of the feet motion are plotted in Fig. 6.

Analysing the presented graphical dependencies (Figs. 6,7) and comparing them with the results of analytical investigations (Fig. 5), we can state about their satisfactory coincidence. This substantiates the adequacy of the derived mathematical expressions for describing the motion of mobile robotic system with orthogonal walking drive. Some imperceptible differences can be substantiated by some delay in the operation of pneumatic cylinders and by non-zero initial positions of the supporting feet of the walking mechanism. This take place due to the specific peculiarities of simulation process in SolidWorks software. Nevertheless, the average motion speed of the mobile robot equals $0.2 \mathrm{~m} / \mathrm{s}$, the maximal height of the supporting foot lifting equals $0.15 \mathrm{~m}$, and the walking character (Figs. 6, 7) are identical to the ones obtained by numerical modelling (Fig. 5). 


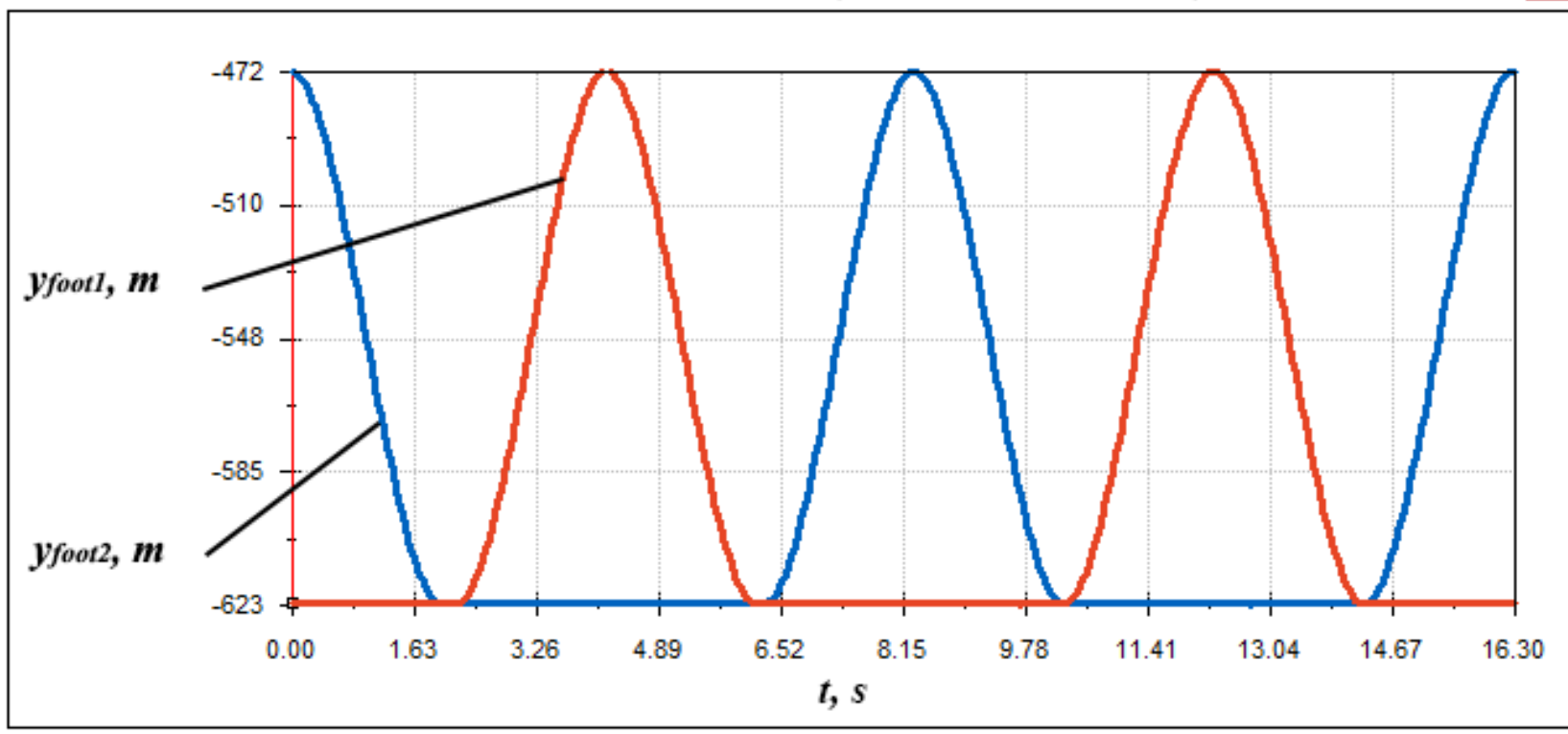

Horizontal displacement of the supporting feet of the walking mechanism

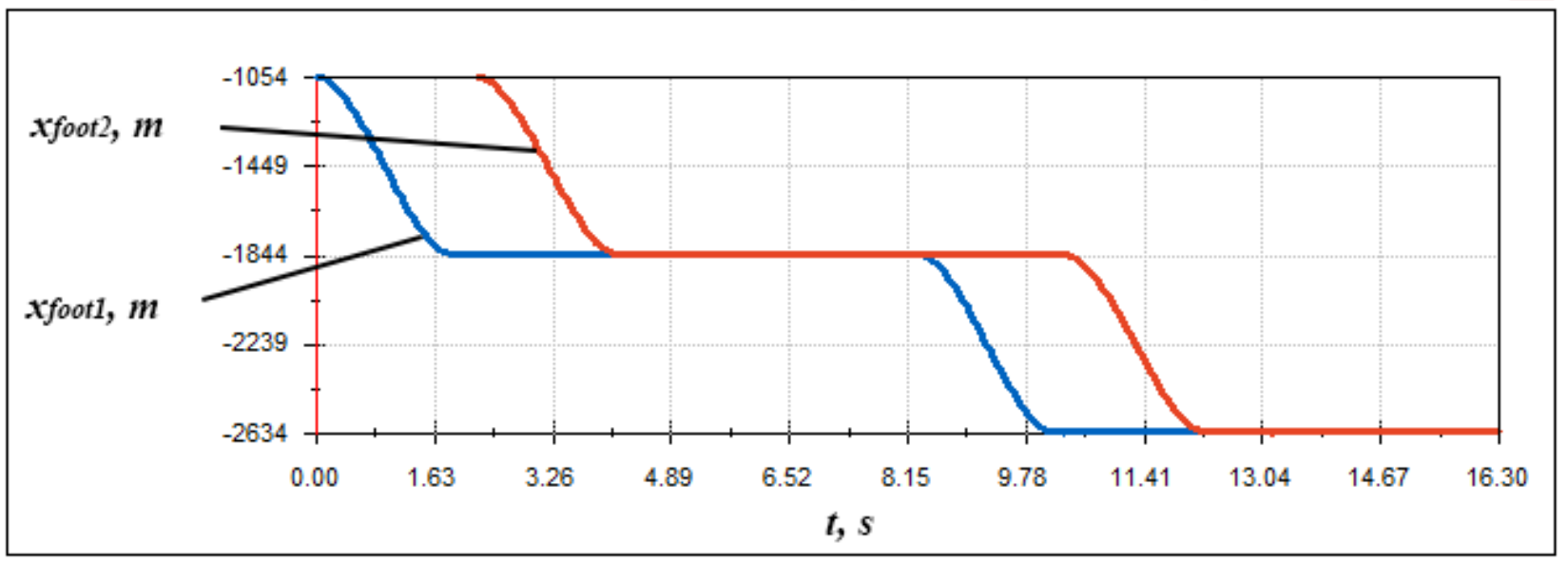

b

Fig. 7. Time dependencies of changing the coordinates of the robot's supporting feet obtained by the results of the robot's motion simulation in SolidWorks software

\section{Simulating the Operation of the Robot's Pneumatic System in FESTO FluidSim Software}

In order to substantiate the adequacy and operation capacity of the proposed principal pneumatic circuit of the mobile robot (Fig. 4), the corresponding simulation model of the pneumatic system was implemented in applied software FESTO FluidSim Pneumatics (Fig. 8). The results of simulation presented in the form of timing diagrams of the pneumatic cylinders operation are shown in Fig. 8. Analysing the obtained results, we can state that the timing diagram obtained by simulation in FESTO FluidSim Pneumatics software satisfactorily corresponds to the theoretical timing diagram (Fig. 3).

\section{Conclusions}

In this paper, the structure of the mobile robotic system with orthogonal walking drive and pneumatic actuation is proposed (see Fig. 1). The robot is equipped by two platforms and eight feet. The basic peculiarities of its operation are considered, and the process of the cyclic walking is described (Fig. 2). Based on results of performed analysis of the walking process, the timing diagram of operation of the actuating pneumatic cylinders was constructed (Fig. 3) and the corresponding pneumatic circuit was developed (Fig. 4). The laws of motion of the main robot's members, which provide its programmable 


\section{Substantiation of Structure and Parameters of Pneumatic System of Mobile Robot ...}

cyclic walking motion in accordance with the substantiated timing diagram of the pneumatic cylinders operation, were derived.

Based on the obtained analytical dependencies, the numerical modelling of the mobile robot's supporting feet was performed in MathCAD software. Under the prescribed input parameters: nominal speed of the piston-rods of the pneumatic cylinders of the platforms' horizontal motion $V_{h}=0.395 \mathrm{~m} / \mathrm{s}$; nominal speed of the piston-rods of the pneumatic cylinders of the supporting feet vertical motion $V_{v}=0.075 \mathrm{~m} / \mathrm{s}$; duration of the one stroke of the walking process $T=2 \mathrm{~s}$; maximal extension of the pistonrod of the pneumatic cylinder of the supporting feet vertical motion $y_{1 \min }=y_{2 \min }=0,15 \mathrm{~m}$, it was established that: 1) the proposed timing diagram of the pneumatic system operation (Fig. 3) is accurately described by the derived equations of the robot's members motion (1);2) at each moment of time, the supporting feet of at least one platform are in contact with the supporting surface; 3 ) the supporting feet of different platforms are not at the same walking phase during the whole walking process; 4) the step length during one cycle of the pneumatic system operation $(8 \mathrm{~s})$ equals $1.58 \mathrm{~m}$. Therefore, the average speed of the robot's motion is $0.2 \mathrm{~m} / \mathrm{s}$ or $0.7 \mathrm{~km} / \mathrm{h} ; 5$ ) the maximal height of the supporting feet lifting (i.e. the maximal height of the obstacle that can be overcome by the robot) is equal to the maximal extension of the corresponding pneumatic cylinder $-0.15 \mathrm{~m}$.

The solid-state model of the robot was designed in SolidWorks software (Fig. 6). Its motion was simulated and the results of virtual experiment (Fig. 7) were compared with the ones of numerical modelling (Fig. 5). The conclusions about their satisfactory coincidence were substantiated. The simulation model of the robot's pneumatic system was implemented in applied software FESTO FluidSim Pneumatics (Fig. 8), and the obtained timing diagram satisfactorily corresponded to the theoretical one (Fig. 3).

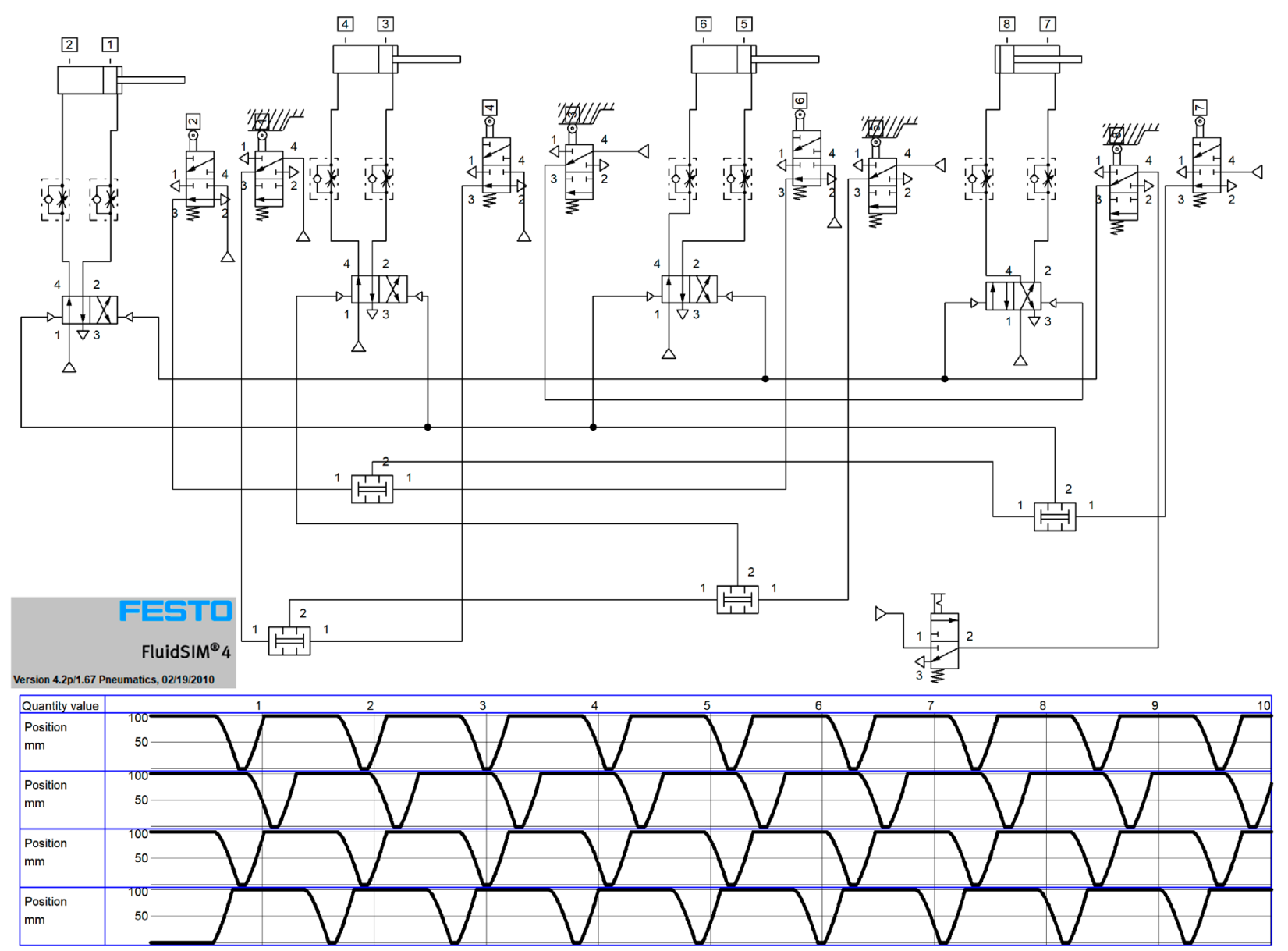

Fig. 8. FESTO FluidSim Pneumatics software window, in which the simulation of the pneumatic circuit operation has been carried out 


\section{Vitaliy Korendiy, Roman Zinko, Diana Muzychka}

\section{References}

[1] B. Deepak, M. Bahubalendruni, and B. Biswal, "Development of in-pipe robots for inspection and cleaning tasks”, International Journal of Intelligent Unmanned Systems, vol. 4, no. 3, pp. 182-210, 2016.

[2] Xiangxin Li, and Xinglun Tang, "Position error calibration analysis of a series orthogonal structure robot", Modern Machinery, issue 01, TP242, 2017.

[3] Nazim Mir-Nasiri, Hudyjaya Siswoyo J., and Md. Hazrat Ali, "Portable autonomous window cleaning robot", Procedia computer science, vol. 133, pp. 197-204, 2018.

[4] A. E. Gavrilov, V. V. Zhoga, and P. V. Fedchenkov, "Synthesis of optimal program law for movement of a robot with orthogonal walking drives", Journal of Computer and Systems Sciences International, vol. 50, issue 5, pp. 847-857, October 2011. https://doi.org/10.1134/S1064230711050108

[5] V. V. Zhoga, A. E. Gavrilov, and A. V. Eremenko, "Optimalnyy zakon gorizontalnogo peremeshcheniya mobilnogo robota s ortogonalnymi shagayushchimi dvizhitelyami" ["The optimum law of horizontal moving of the mobile robot with orthogonal walking movers"], Izvestiya Volgogradskogo gosudarstvennogo tekhnicheskogo universiteta [News of Volgograd State Technical University], vol. 8, no. 6, pp. 28-32, 2010. [in Russian].

[6] V. Zhoga, V. Skakunov, I. Shamanov, and A. Gavrilov, "Programmable Movement Synthesis for the Mobile Robot with the Orthogonal Walking Drivers", in Advances in Mechanical Engineering. Lecture Notes in Mechanical Engineering. Springer, Cham, 2016, pp. 135-147. https://doi.org/10.1007/978-3-319-29579-4_14

[7] V. V. Zhoga, R. V. Aniskov, A. A. Merkulov, and V. N. Skakunov, "Sistema upravleniya elektroprivodom shagayushchego robota s ortogonal'nymi dvizhitelyami" ["Control system of electric-powered walking robot with orthogonal drivers"], Izvestiya Volgogradskogo gosudarstvennogo tekhnicheskogo universiteta [News of Volgograd State Technical University], vol. 21, no. 12, pp. 157-162, 2014. [in Russian].

[8] A. Ye. Gavrilov, A. S. Danshin, and A. A. Burkhanov, "Avtonomnaya robotizirovannaya shagayushchaya platforma dlya monitoringa okruzhayushchey sredy" ["Autonomous robotic walking base for environment monitoring"], Izvestiya Volgogradskogo gosudarstvennogo tekhnicheskogo universiteta [News of Volgograd State Technical University], vol. 21, no. 12, pp. 153-157, 2014. [in Russian].

[9] V. V. Zhoga, V. N. Skakunov, A. V. Filimonov, and D. V. Golubev, "Dinamika marshevykh rezhimov dvizheniya robota s ortogonal'nymi dvizhitelyami" ["Dynamics of the marching modes of motion of the robot with orthogonal movers"], Izvestiya Volgogradskogo gosudarstvennogo tekhnicheskogo universiteta [News of Volgograd State Technical University], vol. 16, no. 8, pp. 14-21, 2013. [in Russian].

[10] V. V. Zhoga, and P. V. Fedchenkov, "Mobilnyy avtonomnyy robot s shagayushchimi ortogonalnopovorotnymi dvizhitelyami" ["Mobile autonomous robot with walking orthogonal-turning drives"], Vestnik Nizhegorodskogo universiteta im. N. I. Lobachevskogo [Bulletin of Lobachevsky University of Nizhni Novgorod], vol. 4, no. 5, pp. 2160-2162, 2011. [in Russian].

[11] V. M. Korendiy, O. Yu. Kachur, V. I. Gurey, and O. V. Lanets, "Modelyuvannya rukhu mobilnoho robota z pnevmatychnym pryvodom ta ortohonalnym krokuyuchym rushiyem" ["Modelling the motion of mobile robot with pneumatic drive and orthogonal walking mover"], in Proc. of $14^{\text {th }}$ International Symposium of Ukrainian Mechanical Engineers in Lviv, Lviv, Ukraine, May 23-24, 2019, pp. 79-80. [in Ukrainian].

[12] I. L. Krivts, and G. V. Krejnin, Pneumatic Actuating Systems for Automatic Equipment: Structure and Design. Boca Raton: CRC Press, 2016. 